\title{
Desarrollo territorial y descentralización. El desarrollo en el lugar y en las manos de la gente
}

\begin{abstract}
This article offers a review of some decentralization related topics in Latin America, using a more conceptual than empirical approach. In the first section, the ambiguity of the concept of decentralization, often confused with desconcentration andlor delocalization, is described. The second section argues that centralism in Latin America is a path dependent phenomenon, very related to our countries' culture. The third section comments current decentralization dynamics, linking them to four forces: Scientific and Technological Revolution, State reform, civil society demands and neoliberalism privatization trends. The fourth section discuss the need of structurating a new cognitive corp, in order to use efficiently the spaces opened by decentralization process, improving territorial growth and development. The last section claims that the modernization of social

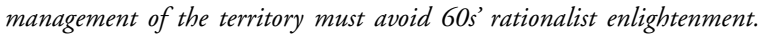

Keywords: Descentralization, civilsociety, development, territiory, State, knowledge.

\section{Resumen}

\begin{abstract}
Este artículo revisa algunos aspectos vinculados a la descentralización en América Latina, desde un enfoque conceptual más que empírico. Una primera sección observa la ambigüedad del concepto de descentralización, a menudo confundido con desconcentración y/o deslocalización. Una segunda sección sostiene que el centralismo es, en América Latina, un fenómeno "dependiente de la trayectoria”, muy ligado a la cultura de nuestros países. Una tercera sección comenta la dinámica de la descentralización en la actualidad, asociándola a cuatro fuerzas: la Revolución Científica y Tecnológica, la reforma del Estado, las demandas de la sociedad civil y las tendencias privatizadoras del neo-liberalismo. La cuarta sección discurre acerca de la necesidad de estructurar un nuevo cuerpo cognitivo para usar con eficacia los espacios abiertos por el proceso descentralizador en el fomento del crecimiento y del desarrollo en el territorio. La quinta y última sección previene acerca de la necesidad de modernizar la gestión social del territorio sin volver a caer en el iluminismo racionalista de los ' 60.
\end{abstract}

Palabras clave: descentralización, desconcentración, sociedad civil, desarrollo, territorio, Estado, conocimiento. 
Creo que la extrema centralización del poder político acaba por debilitar a la sociedady, a la larga, al propio gobierno. Pero no niego que una fuerza social centralizada esté capacitada para ejecutar fácilmente, en tiempos y lugares dados, grandes empresas.

Alexis de Tocqueville, "La democracia en América”.

\section{La ambigüedad intrínseca de la descentralización}

$\mathrm{E}$ s muy certera la reflexión del abogado, diplomático y político francés del siglo XIX, a quien muchos consideran el padre de la descentralización occidental, si se entiende que el par centralización/descentralización no configura un par estrictamente dicotómico, sino más bien uno en el cual sus polos representan los extremos de un arco de situaciones en que cada posible punto intermedio es una combinación de ellos que responde a un determinado contexto histórico, y que es funcional a ese contexto y no a otros. Como lo afirma Work (2001), "la descentralización no es una alternativa a la centralización” (30).

Si se comparte la afirmación anterior se daría un gran paso hacia la desmitificación del proyecto descentralizador: ni pensamiento voluntarista como se suele calificarlo desde una izquierda anclada en el pasado, ni deus ex machina de la democracia y del desarrollo, como se le presenta desde el otro extremo ideológico. La combinación o proporción áurea de centralización y descentralización depende del alcance del siempre cambiante contrato social entre el Estado y la sociedad civil, contrato social, dígase de paso, extremadamente feble en

\footnotetext{
* Presidente-Ejecutivo del Centro de Anacción Territorio y Sociedad (CATS), profesor Invitado del Instituto de Desarrollo Regional (IDER) de la Universidad de la Frontera, miembro del Consejo Científico del Instituto de Desarrollo Regional de Sevilla. E-mail: sboisier@vtr.net

* Documento preparado originalmente para el Seminario "Descentralización de sectores sociales: Nudos críticos y alternativas", organizado por los Ministerios de la Presidencia, de Educación, y de Salud del Perú y celebrado en Lima, Perú, entre el 9 y el 11 de abril de 2002. Recibido el 15 de julio, aprobado el 2 de agosto.
}

América Latina, por debilidad congénita de uno de los firmantes, la sociedad civil.

La descentralización es un concepto tanto teleológico como instrumental. Es fin y medio simultáneamente y ello ha contribuido a un cierto nivel de confusión conceptual en el debate descentralizador (Boisier, 1991).

En particular, y bajo el frondoso árbol político del liberalismo, específicamente en la corriente ideológica originada en la matriz doctrinaria del humanismo cristiano (del "catolicismo social", como se le denominaba décadas atrás), la descentralización societal representa la aplicación en la práctica del principio político de subsidiaridad, de acuerdo al cual cada organización social es competente para intervenir sobre su propio ámbito (funcional o territorial), transfiriendo "hacia arriba" sólo aquello que el bien común o la tecnología establezca como responsabilidad del ente mayor. Entiéndase, en este marco, la subsidiaridad como indisolublemente apareada con el principio moral de solidaridad, también tanto en el plano funcional como territorial. La subsidiaridad envuelve el reconocimiento del ser humano como persona humana en su doble condición de individualidad y sociabilidad, es decir, como sujeto de su propio destino logrado siempre en asociación con otros; se es persona humana sólo entre personas humanas. La solidaridad, a su turno, es una expresión práctica del amor, en el amplio sentido en que Humberto Maturana emplea este concepto, basado en el reconocimiento, entendimiento y cooperación con "el otro".

El entender la descentralización tanto como una cuestión instrumental así como finalista permite explicar su carácter inasible, su conversión en bandera de gobierno (que privilegia su dimensión instrumental) como de oposición (privilegiando su dimensión finalista), rara vez aceptada en su dualidad (medio y fin al mismo tiempo).

En verdad la descentralización, por lo menos entre nosotros en América Latina, se presenta como un concepto de elevada ambigüedad cotidiana, ya que es frecuente que se hable indistintamente de descentralización o de desconcentración; incluso a veces se confunde la mera deslocalización (el cambio de ubicación geográfica de un ente) con la descen- 
tralización, tal como se podía apreciar en Chile en relación al traslado del Congreso Nacional desde Santiago a Valparaíso.

Debe ser claro que aun cuando los procesos de desconcentración y descentralización se encuentren frecuentemente en un mismo continuo, el primero de ellos alude a una cesión de capacidad de decisión desde un nivel jerárquico dado a otro inferior dentro del mismo organismo, tratándose en consecuencia de una cuestión interna que no requiere sino la voluntad del nivel jerárquico superior; el segundo, la descentralización, supone la creación de un ente distinto de aquél del cual se va a transferir capacidad decisoria, y ello a su vez supone la concesión de personalidad jurídica propia, de recursos y de normas propias de funcionamiento.

Puede agregarse todavía, ya en el terreno propio de procesos de descentralización, que éstos pueden dar origen a tres modalidades "puras" de descentralización: (a) funcional, cuando se crea un ente con personalidad jurídica, normas y presupuesto propio, estando su accionar limitado a una función, actividad o sector (por ejemplo, una empresa pública generadora de energía eléctrica); (b) territorial, cuando se crea un ente con las características señaladas, de alcance multisectorial, pero cuya actuación se restringe a un espacio político/administrativo definido (por ejemplo, un gobierno regional); y (c) política, cuando cumplidos los requisitos básicos, la generación del ente deriva de procesos electorales populares, secretos e informados, como puede ser, por ejemplo, un Municipio. De mayor interés en esta ocasión resulta referirse a las modalidades "mixtas" que se pueden concebir al combinar por pares las tres anteriores, y de entre ellas la combinación de una descentralización simultáneamente territorial y política (un gobierno regional electo) es la de máximo interés, siendo al mismo tiempo una sentida aspiración en los países de régimen político unitario. Por cierto, clasificaciones como la anterior son casi tantas como autores (Cheema \& Rondinelli, 1983; Finot, 2001, entre otros).

Otra cuestión, a mi juicio de la mayor importancia conceptual, es la siguiente. En gran parte del debate cotidiano la descentralización es entendida fundamentalmente como una reforma de la administración pública, lo que en verdad en la práctica vendrá a ser simplemente una desconcentración, incluso territorial, del aparato tecno-burocrático de gobierno; en otros casos la discusión sube de nivel y se interpreta la descentralización como una reforma del Estado, envolviendo en este caso un cambio estructural en la articulación del Estado con la sociedad civil y en la distribución espacial del poder, como lo fue en su momento, la puesta en práctica de la Ley Orgánica de Gobierno y Administración Regional de Chile (LOCGAR 19.175 de 1992); pocas veces el debate alcanza el verdadero nivel en que hay que plantear esta cuestión, es decir, como un cambio estructural societal, que como tal involucra a todo el tejido político y social de una nación, un nuevo contrato social. De nuevo, Work (2001) dice: "La descentralización es mucho más que una reforma del sector público, de la administración o del funcionalismo. Envuelve el papel y las relaciones de todos los actores societales, sean gubernamentales, del sector privado o de la sociedad civil” (30).

En los dos casos últimos es clara la naturaleza política de la descentralización, ya que se trata de una modificación en el patrón de distribución del poder, el recurso colectivo por antonomasia. Por ello tiene razón el constitucionalista venezolano Brewer-Carías (1998) al sostener con energía el carácter político del proceso, saliendo al paso de quienes, por distintas razones, ven sólo la dimensión administrativa. Parte de este problema se explica porque en algunos casos son las propias leyes fundamentales las que en su articulado hablan de regímenes unitarios con descentralización administrativa que la ley regulará, como sucede precisamente en la Constitución de Chile y en la de Venezuela.

Inescapable resulta también una breve referencia a la relación entre descentralización y democracia, relación preñada de ambigüedad. En 1989 la ahora extinta Comisión Presidencial para la Reforma del Estado de Venezuela (COPRE) publicaba un libro titulado precisamente "La descentralización. Una oportunidad para la democracia” (COPRE, 1989), al tiempo que en las postrimerías del régimen militar en Chile, en ese mismo año, afirmábamos precisamente lo contrario, al sostener en un artículo de prensa publicado por el diario El Sur (Concepción, Chile, 1989) que la democracia era una oportunidad para la descentralización. Ambos títulos son igualmente verdaderos. 
Es casi evidente que una democracia madura supone una amplia distribución social del poder político, o sea, supone una descentralización, pero es un error común asignar causalidades unidireccionales, como si un proceso necesariamente generase linealmente el otro, desconociéndose el carácter recursivo de ambos. Desde luego, en términos territoriales la transferencia de poder a regiones, por ejemplo, puede resultar completamente antidemocrática si en tales regiones no existe un receptor socialmente adecuado, en cuyo caso el poder transferido sólo reforzaría estructuras oligárquicas y clientelísticas. De nuevo, una relación entre descentralización y democracia debe ser puesta en su contexto histórico, porque en no pocos casos la centralización ha sido un requisito para precisamente dar paso posterior a una democracia descentralizada, si la centralización previa tuvo por propósito consolidar la construcción de un Estado/nación, como podría ser el caso de Francia en Europa y de Chile en América Latina. Como lo afirmaba desde la Presidencia de Francia F. Mitterrand, "Francia ha tenido necesidad de un poder fuerte y centralizado para hacerse. Ella necesita, hoy día, un poder descentralizado para no deshacerse" (DATAR, 2000: 17).

Un demócrata incuestionable como BrewerCarías (1998) dice, refiriéndose al período inmediato a la caída de Pérez Jiménez: "La democracia no habría durado una semana, fue necesario implantar la democracia con un sistema centralizado, de manera que el centralismo per se no es malo, fue el instrumento que afianzó la democracia”.

Lo único claro en esta materia es que la descentralización bien entendida es incompatible con regímenes autoritarios, sean de izquierda o de derecha. Ello porque la descentralización significa competir por espacios políticos, con la posibilidad previsible que la competencia sea ganada por sectores opositores al gobierno autoritario, produciéndose una incoherencia lógica inadmisible a priori y a posteriori. Quizás debido a ello es que el General Pinochet acostumbraba a decir durante su gobierno que "la administración se descentraliza, el poder jamás”. ¡A confesión de partes, relevo de pruebas!

Imposible dejar de mencionar la confusión, intencionadamente propalada por los centralistas a ultranza, entre descentralización político/territorial y federalismo, una cuestión que es agitada de tanto en cuando en Chile, aludiendo al supuesto peligro que para la concepción del Estado unitario significaría hacer de las regiones entes tanto territorial como políticamente descentralizados en virtud de llegarse, por esa vía se dice, a un sistema federal "ajeno por completo a nuestras tradiciones" (como si en el siglo XIX no se hubiera propuesto y ensayado una Constitución Federal en 1826). El unitarismo se muestra como un modelo sacrosanto, y el federalismo se presenta como una perversa contrapartida. De nada sirve dar unas cuantas lecciones sobre sistemas confederados, federados y unitarios, y menos aún mostrar los varios ejemplos de países que se declaran como constitucionalmente unitarios y territorial y políticamente descentralizados al mismo tiempo, como Italia, España y Bélgica en Europa o como Colombia en América Latina.

\section{El centralismo como fenómeno dependiente de la trayectoria ${ }^{1}$}

América Latina posee una "cultura centralista", en la expresión de Véliz (1984), como resultado, según este autor, del hecho de no haber existido en América Latina cuatro grandes fenómenos sociales europeos: ni un cambio social como el provocado por la Revolución Industrial, ni un cambio político como el provocado por la Revolución Francesa, ni un cambio religioso como el provocado por la Reforma ni, finalmente, un sistema de reparto territorial del poder tal como el feudalismo. La ausencia de tales estructuras y procesos aunados a la modalidad de la conquista ibérica habría representado el caldo de cultivo del actual centralismo latinoamericano. En tal marco general hay amplio espacio para la diferenciación entre países.

A esta tesis hay que agregar un elemento a mi juicio central, por lo menos en los países de la vertiente andina. Me refiero al régimen de

\footnotetext{
${ }^{1}$ La expresión "dependiente de la trayectoria" es una adaptación del término inglés path dependence, muy utilizado en los estudios sobre capital social, y se refiere a la construcción histórica de ciertos procesos. En tal caso estos procesos se incrustan en la cultura. Véase Granovetter (1973).
} 
inquilinaje campesino, heredero de la encomienda española. Tal régimen, con no pocas características de la servidumbre de la gleba, sometió a la mayoría de la población hasta bien entrado el siglo XX a un tipo de relación laboral rural tremendamente dependiente de la sujeción servil del inquilino al dueño de la hacienda, al punto de crear, en el imaginario campesino, la figura del padrepatrón, dueño de la hacienda, empleador, pagador y también proveedor de servicios (religiosos, comerciales, de salud, de educación). Cuando este régimen se quiebra y ya en el tercer decenio del siglo XX se inicia el intenso y sostenido proceso de migración rural-urbana derivado de la industrialización incipiente, éste no se acompaña de un paralelo proceso de educación cívica, que debería haber enseñado cómo enfrentar una vida urbana e industrial.

Puedo imaginar entonces a un campesino perdido en la capital, parado en la plaza frente al Palacio de Gobierno, mirando sin ver y preguntándose en su soledad: ¿¿dónde está mi padre-patrón? Puedo ver también que en ese momento se abre una ventana en Palacio apareciendo un burócrata, que observa al campesino concluyendo que precisamente ahí su buena suerte le ha colocado al frente un "cliente" que lo ayudará a consolidar su clase emergente. Lo llama y le dice: yo soy ahora tu padrepatrón, sólo que me llamarás padre-Estado, porque soy dueño del país. Así, limpiamente, la mentalidad dependiente rural dará paso, sin solución de continuidad, a la mentalidad dependiente urbana, por ausencia de un proceso de socialización. Me parece obvio que la dependencia desea carnalmente al centralismo y a la inversa. Hay una concupiscencia mutua.

Transformado entonces el centralismo en un fenómeno históricamente construido es fácil concordar en que ahora nos enfrentamos con una cuestión cultural, de difícil remoción.

Tal vez por ello el ex Presidente de Chile, Eduardo Frei Ruiz-Tagle (1996), citaba en su libro "Ideas para el diálogo democrático" precisamente a este autor: "El destino del proyecto descentralizador en América Latina está condicionado al reconocimiento del carácter cultural de la centralización y, por tanto, al carácter cultural de su contrapartida: la descentralización. Esta presupone un cambio cultural, una modificación del patrón de alteridad tan propio de nuestra población (siempre buscamos a otro, al 'alter', para que nos resuelva nuestros problemas) y ello significa [asumir] un modelo de comportamiento individual y social basado en la autorresponsabilidad y en la subsidiaridad. Pero no se cambia una cultura por decreto, sino por enseñanza y vivencia desde la infancia. Desde la escuela primaria hay que enseñar a 'vivir descentralizadamente' porque simplemente ello es desconocido en América Latina” (248).

La descentralización se puede crear por decreto o por ley en sus aspectos formales, pero no se puede sacar de la cabeza de la gente el centralismo mediante idéntico mecanismo. Hay pues, una gran asimetría entre ambos desde el punto de vista de su construcción/deconstrucción.

\section{La dinámica de la descentralización}

La megatendencia descentralizadora no se explica a sí misma, ella es causada o empujada por otras cuatro fuerzas primarias que deben ser develadas para entender la naturaleza misma de la descentralización.

En primer lugar, la descentralización es empujada por la Revolución Científica y Tecnológica (RCT), la que operando principalmente mediante la microelectrónica (que ya da paso a la nanoelectrónica), modifica profundamente el modo de producción industrial manufacturera, los sistemas de comunicaciones y los sistemas de transporte. Todos estos cambios se potencian entre sí para crear un ambiente más favorable (a veces imprescindible) para la introducción de sistemas decisorios descentralizados.

En relación a la producción industrial es suficiente observar el impacto sintético más importante de la RCT sobre ella: la actual posibilidad de segmentar un proceso manufacturero (anteriormente considerado como una unidad linealmente estructurada), tanto en términos funcionales (dando lugar a varios sub-procesos) como territoriales (dispersando las fábricas en lugares discontinuos del 
globo $)^{2}$. Se configura el paso de la empresa individual y localizada en un punto a un conglomerado en red con localización múltiple. Es claro que en tal esquema de funcionamiento horizontal, los responsables de cada planta deben necesariamente disponer de un amplio espacio de autonomía decisoria a fin de ajustarse a la velocidad de la globalización, y por tanto será necesario introducir esquemas descentralizados en el sistema de toma de decisiones del conglomerado ${ }^{3}$.

En relación a las comunicaciones, es obvio comentar que la RCT ha producido una reducción brutal en el costo de transmisión de datos e imágenes, transformando el "costo de la fricción de la distancia”, la antigua expresión de Walter Isard, en una nimiedad, y por tanto reduciendo significativamente la necesidad de integración vertical y centralización asociada a los mecanismos cara a cara de toma de decisiones. Estar lejos o cerca ha perdido relevancia en la actual geografía económica, y si estar lejos significa el beneficio de reducción de costos laborales u otros, entonces la descentralización viabilizada por la tecnología es extremadamente útil.

De un modo similar, la RCT ha modificado en profundidad los sistemas de transporte, reduciendo costos, haciendo irrelevante la distancia geográfica en muchos aspectos. En el transporte marítimo la introducción del contenedor, de los sistemas de roll-on-roll-off, la integración inter-modal y las reformas laborales portuarias han bajado considerablemente los costos, en tanto que en el transporte aéreo los aviones de fuselaje ancho, los motores más eficientes y los sistemas ILS de aterrizaje y despegue han provocado efectos similares, y en el transporte ferroviario las nuevas tecnologías de trenes de

${ }^{2}$ Los ejemplos empíricos sobran: la fabricación del automóvil Ford Escort en Europa (16 lugares diferentes para elaborar partes y componentes), la fabricación del avión AIRBUS (seis lugares), etc. Obsérvese la notable recuperación, a la luz de la RCT, de la antigua tecnología suiza de fabricación de relojes, completamente horizontal y en red, si bien a una escala micro.

${ }^{3}$ Confunde a muchos especialistas el hecho de que esta descentralización se da la mano con otros procesos dentro del mismo conglomerado: descentramiento (desplazamiento territorial) de la cadena de valor y concentración y centralización de ciertos segmentos estratégicos de esa misma cadena. alta velocidad (TGV, AVE, Shinkansen, etc.) apuntan en la misma dirección, sin mencionar siquiera la tendencia a reemplazar el desplazamiento de materiales por el de información. Todos estos procesos, al reducir el costo de la distancia, facilitan el descentramiento de actividades y la descentralización.

En segundo lugar, la descentralización es empujada por la reforma del Estado, al menos en América Latina. Recuperada la democracia formal en toda América Latina a comienzos de los ' 90 , se ha tratado de no reimplantar el viejo estilo de ella reemplazándolo por un nuevo estilo que apuesta a la sociedad civil como el nuevo y multitudinario agente conductor del proceso permanente de cambio. Somos todos nosotros y no ya un agente único (Estado, Partido, Iglesia, Ejército, Proletariado, etc.) quien conduce este proceso, y para que ello sea posible hay que devolver a las instituciones de la sociedad civil (todos nosotros) su autonomía históricamente perdida (a manos del Estado principalmente), y ello equivale a la descentralización societal. Por tanto hay encima de la mesa social una oferta descentralizadora.

En tercer lugar la descentralización se alimenta de una creciente demanda autonómica por parte de organizaciones de la misma sociedad civil, especialmente organizaciones de base territorial. Tal demanda incluso puede transformarse en una patología disolvente del propio Estado nacional, pero el hecho es que estas organizaciones creen, legítimamente, haber alcanzado una mayoría de edad y no están dispuestas a seguir aceptando que "otros" tomen decisiones que están dentro de su ámbito de control. Por tanto en la mesa social hay también una demanda descentralizadora. Un punto a elucidar es precisamente el cruce de ambas "curvas", la de oferta y la de demanda.

En cuarto lugar, la descentralización es reforzada en cierta manera por las tendencias privatizadoras vigentes. Hay que ser cuidadoso al explicar este aspecto, que en el fondo es muy simple. Si el acto privatizador permite el surgimiento de un nuevo sujeto decisor independiente en el sistema o país en cuestión, por ejemplo, un inversionista extranjero que no estaba presente o una agrupación civil formada de manera $a d-h o c$ para estos efectos, el resulta- 
do es una ampliación del número de decisores independientes presentes en el sistema y ello, desde el punto de vista estricto de la teoría económica, significa ampliar la descentralización ${ }^{4}$. Si el acto privatizador no genera esta situación, la privatización probablemente sólo contribuye a aumentar la concentración de activos y su efecto descentralizador resulta impredecible. Obsérvese de paso la asociación lógica que surge entre neo-liberalismo (o el Consenso de Washington) y descentralización. ¿Algún parecido con los procesos actuales en América Latina?

Finalmente hay que agregar otra fuerza detrás de la descentralización y que tiene que ver con la lógica de la globalización: no se puede ser competitivo en el mundo actual con estructuras centralizadas porque no poseen la velocidad requerida ahora. En otras palabras, la apertura externa de la globalización obliga forzosamente a una apertura interna de carácter político (Boisier, 1996).

\section{Descentralización y territorio: una intersección para potenciar el desarrollo y la democracia}

Por una variedad de razones los gobiernos nacionales, normalmente altamente centralizados, sean federales o unitarios, están transfiriendo diversas funciones ( $\mathrm{y}$ en menor medida los recursos necesarios) a una multiplicidad de gobiernos subnacionales -regionales, provinciales y sobre todo municipales- bajo un imperativo que parece ser: ahora ocúpese usted de hacer gobierno en su jurisdicción, transferencia que encuentra en principio una alegre recepción en las propias entidades territoriales, que ahora demandan mayor autonomía, como fue señalado. Oferta y demanda se cruzan en el territorio y en la función. Hay que agregar que la expresión "hacer gobierno" resulta ahora casi un sinónimo de "hacer desarrollo".

También por otra variedad de razones los territorios están siendo revalorizados en la globalización (Boisier, 2001; Morgan, 2001; OECD, 2001), al punto de convertirse paulatinamente en los nuevos

\footnotetext{
${ }^{4}$ Como cualquier economista sabe, el mercado perfecto de los textos es totalmente descentralizado.
}

actores de la competencia internacional por capital, por tecnología y por mercados, como tan claramente se observa en la Unión Europea. Es claro que para poder competir con posibilidades de terminar en una posición "ganadora", los territorios organizados, cualquiera sea su denominación político-administrativa, requieren de una autonomía impensable en el pasado reciente, autonomía sólo concebible en el marco de un proyecto nacional descentralizador.

La cuestión central radica en que el cruce de la oferta y de la demanda de descentralización territorial se realiza precisamente en un punto de encuentro en el cual confluyen, por un lado, el cambio en las funciones de regulación del gobierno nacional, en el sentido de reservarse éste de ahora en adelante sólo las funciones más estrictamente nacionales (política monetaria, fiscal, comercial, marco de competencia, transparencia, etc.) entregando, como se señaló, la función de fomentar el crecimiento y el desarrollo a entes territoriales, y por otro, la percepción de los territorios (regiones, provincias, comunas) de ser ellos los responsables de activar los varios mecanismos que operan actualmente como factores causales de su propio crecimiento y de su desarrollo, y de su posicionamiento en la globalización. Los territorios deben asumir un cúmulo de responsabilidades sobre las cuales no tienen generalmente una acumulación de prácticas históricas, en parte debido a la rapidez del cambio en la sociedad actual. Esta constatación coloca, en el contexto de la actual sociedad del conocimiento, la cuestión del conocimiento en el cruce mismo de la descentralización y del desarrollo territorial.

Surge entonces una tesis de enormes repercusiones: la gestión territorial conducente a provocar un mejoramiento en la calidad de vida de la gente, a una disminución de las diferencias en esa misma calidad de vida entre grupos poblacionales localizados en distintas partes del país, a intentar colocar al territorio en cuestión en una posición "ganadora" 5 -todo lo cual presupone una descentralización efectiva- exige realmente crear un marco cognitivo nue-

\footnotetext{
${ }^{5}$ Reducir las disparidades territoriales ex-ante tiene que ver con la equidad y con la libertad en un sentido amplio. La característica de "ganador" o "perdedor" de los territorios en el juego globalizador es mucho más compleja que una mera posición estadística.
} 
vo, ya que el conocimiento que sobre estas cuestiones pudiese haberse creado en el pasado no sirve ni en el presente ni menos a futuro, por obsolescencia ${ }^{6}$.

Sostengo que este nuevo marco cognitivo, indispensable para respaldar una acción con probabilidad de éxito, incluye dos formas cognitivas: un conocimiento estructural, capaz de enseñarnos que todo territorio organizado es simultáneamente un sistema, que es un sistema considerablemente abierto, y que es un sistema complejo en el sentido del paradigma de la complejidad; $y$ un conocimiento funcional que nos permita descubrir y entender la causalidad y la dinámica contemporánea de los dos procesos de cambio social más importantes para todo territorio, el crecimiento económico y el desarrollo societal. Ello lleva a investigar cómo se articula un territorio con los procesos globales que están en marcha en el mundo (el nuevo entorno) y a descubrir las causalidades contemporáneas del crecimiento y del desarrollo (el nuevo interno). La Figura 1 ilustra esta primera propuesta.

Hay que observar la magnitud de la tarea propuesta ya que no se trata sólo de declarar, por ejemplo en un documento que sea una propuesta de desarrollo de un territorio, que efectivamente se tiene entre manos una cuestión sistémica, abierta y com- pleja. Se trata de comprender el significado que estos conceptos tienen para la acción, y ello supone un verdadero reentrenamiento mental y un cambio paradigmático imbricado en el propio sistema educacional.

Si se razona ahora en relación a la segunda columna de la Figura 1, es decir, en relación al conocimiento funcional, es preciso comenzar por conocer la estructura del nuevo entorno, configurado, como se dijo, por una serie de procesos mundiales vinculados a la globalización. Este nuevo entorno para cualquier región se construye diariamente a partir de la configuración de tres nuevos escenarios: contextual (relacionado con los procesos de apertura comercial externa y apertura política interna), estratégico (vinculado al surgimiento de una nueva geografía altamente virtual y a nuevas modalidades de gestión territorial) y político (modernización del Estado y reinvención de los gobiernos territoriales). La Figura 2 muestra estos conceptos.

El nuevo interno busca responder, como se indicó, a preguntas que cuestionan acerca de cuáles son los factores que en la contemporaneidad determinan los procesos de crecimiento económico y de desarrollo en un territorio.

Figura 1. Tipos de conocimiento para la acción territorial.

\begin{tabular}{|l|l|}
\hline \multicolumn{1}{|c|}{ Conocimiento Estructural } & \multicolumn{1}{c|}{ Conocimiento Funcional } \\
\hline $\begin{array}{l}\text { Debemos entender que toda región es un siste- } \\
\text { ma, que es además un sistema abierto y que por } \\
\text { añadidura es un sistema complejo. }\end{array}$ & $\begin{array}{l}\text { Tenemos que entender cuál es la estructura ac- } \\
\text { tual (en la globalización) de los procesos de cam- } \\
\text { bio en el territorio. }\end{array}$ \\
$\begin{array}{l}\text { Esto significa que se requieren verdaderos cam- } \\
\text { bios mentales para analizar y para intervenir en } \\
\text { una región. }\end{array}$ & $\begin{array}{l}\text { Hay que conocer el nuevo entorno (cómo se in- } \\
\text { serta una región en su medio externo) y el nuevo } \\
\text { interno (cuáles son hoy los factores causales del } \\
\text { crecimiento económico y del desarrollo societal). }\end{array}$ \\
$\begin{array}{l}\text { Tenemos que aprender análisis de sistemas y te- } \\
\text { nemos que pensar en términos del paradigma de } \\
\text { la complejidad }\end{array}$ & $\begin{array}{l}\text { Siendógeno, hay que tomar nota de los cambios } \\
\text { endón } \\
\text { requeridos en hacer gobierno }\end{array}$ \\
\hline
\end{tabular}

${ }^{6}$ En varios de nuestros países (Bolivia, Colombia, Chile, Perú) aprendimos durante los años ' 60 bastante acerca de las estrategias de polos de crecimiento, derivando el conocimiento de prácticas exitosas o fracasadas. ¿Se atrevería alguien a aplicar esta receta de industrialización en el contexto actual? Quedamos con un conocimiento obsoleto en nuestro maletín de trabajo. 
Figura 2. Nuevo entorno de desarrollo regional.

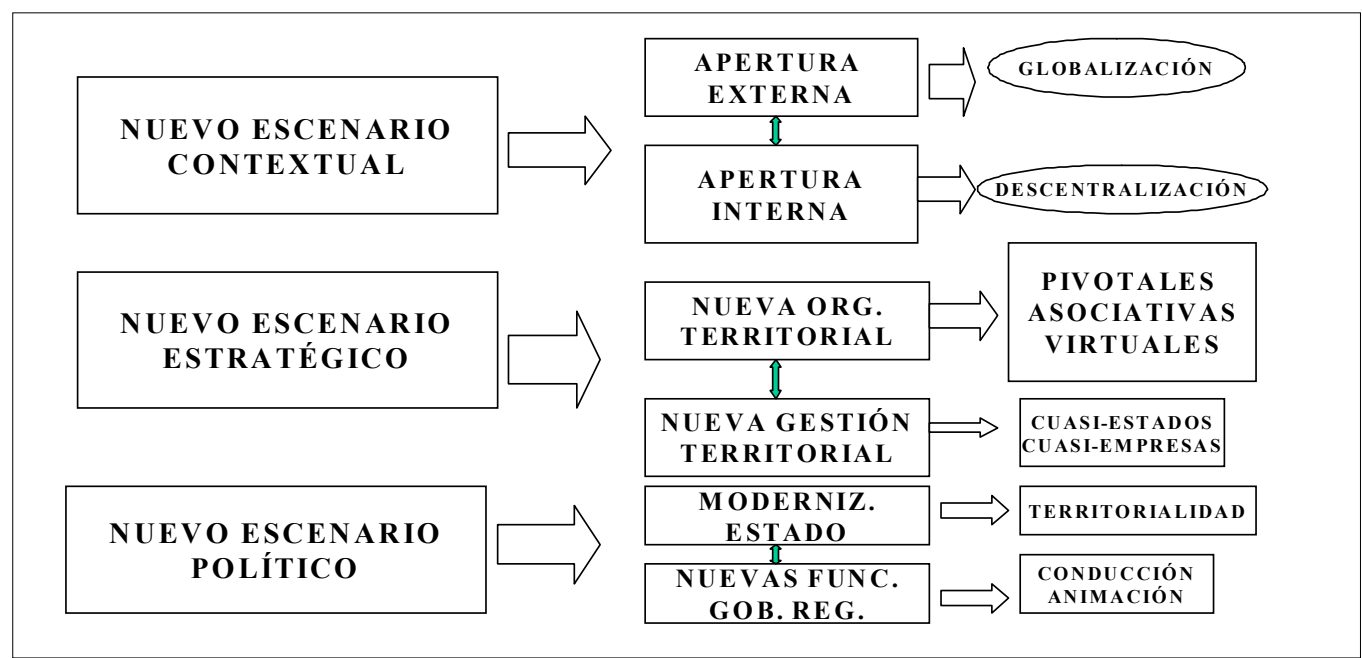

El crecimiento económico territorial depende actualmente de la forma como opera una matriz de seis factores: la acumulación de capital, la acumulación de conocimiento (progreso técnico), la acumulación de capital humano ${ }^{7}$, el "proyecto nacional" y su componente territorial (que asigna papeles estratégicos a cada territorio, afectando su sendero de crecimiento a largo plazo), el cuadro de la política económica nacional global y sectorial que "premia y castiga" implícita y diferenciadamente el crecimiento de cada territorio, y la demanda externa (exportaciones más gasto de no residentes). Cuando estos seis factores se miran desde el punto de vista de los agentes que operan "detrás" de ellos mediante sus decisiones, se concluye que el crecimiento económico territorial es altamente exógeno, los actores se encuentran normalmente fuera de él y por tanto el gobierno territorial no puede controlarlos; a lo sumo puede influenciar sus decisiones, algo directamente dependiente de su capacidad de negociación (parcialmente basada en el conocimiento) y de su capacidad de promoción (también apoyada en el conocimiento). Obsérvese la Figura 3.

El desarrollo societal, por su lado, presenta cuestiones de mucha mayor complejidad. Para empezar,

Figura 3. Crecimiento territorial exógeno.

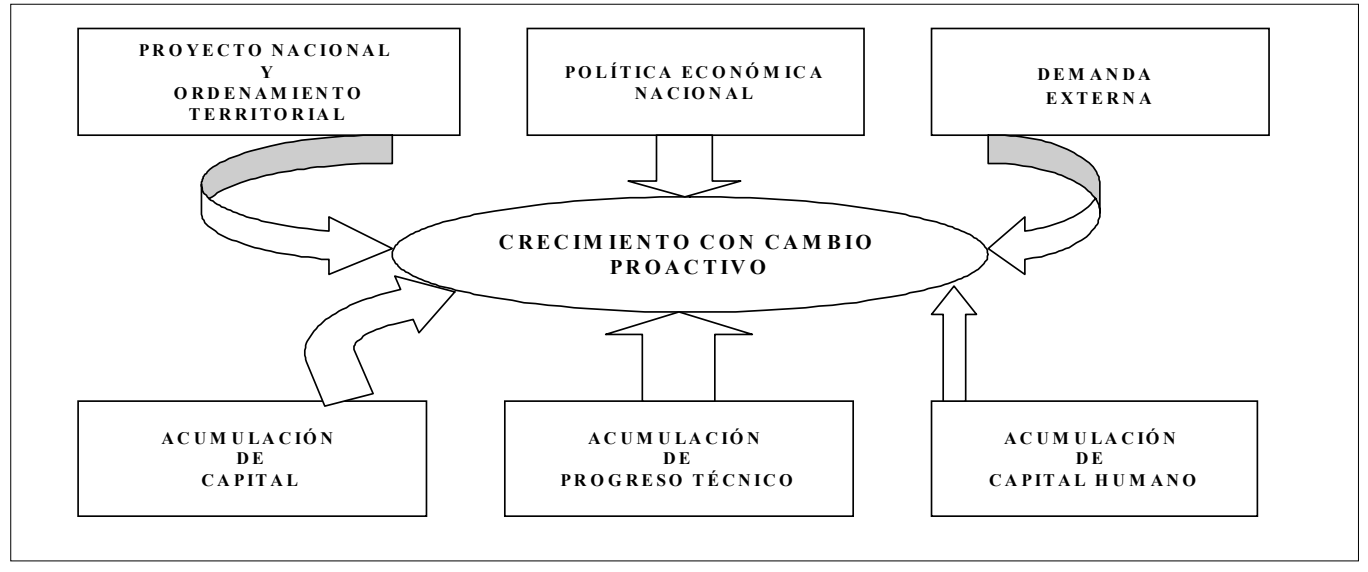

${ }^{7}$ Estos son los factores presentes en la moderna teoría del crecimiento endógeno basado en los rendimientos crecientes a escala. 
ha cambiado por completo nuestra concepción del desarrollo, desde su inicio como un concepto prácticamente sinónimo del crecimiento, hasta su interpretación actual, como un proceso y un estado intangible, subjetivo, constructivista, vinculado a la posibilidad de crear en cada lugar y momento un clima, un contexto, una situación o como se quiera llamar, capaz de potenciar la transformación del ser humano en persona humana, en su individualidad y sociabilidad y en su capacidad permanente de conocer, saber y $\operatorname{amar}^{8}$.

A partir de esta re-conceptualización centrada en la persona humana y en su dignidad como tal (y ello se relaciona con la superación del hambre, del desempleo y de la discriminación, en la versión inicial de Dudley Seers), la búsqueda de los factores causales del desarrollo se ha reorientado hacia un conjunto de ellos, mucho más de carácter intangible que material ${ }^{9}$.

Véase la Figura 4 a continuación.

Es claro que el desarrollo, aun concebido como un "producto" intangible, no puede independizarse por completo de la expansión permanente de una base material (crecimiento), pero hay que rechazar cualquier tipo de causalidad lineal, jerárquica, entre ambos; en particular debe rechazarse la receta neoliberal: primero crecer y luego desarrollarse. Creo que no conocemos todavía la articulación exacta entre crecimiento y desarrollo, y es posible que ella sea de alta complejidad, tal vez como un "rizo" matemático, y podría ser factible que al mismo tiempo su articulación en el tiempo esté descrita por dos cadenas sinoidales entrelazadas como el ADN, sugiriendo que a veces el crecimiento precede al desarrollo y a veces sucede lo contrario.

También se comienza a entender que desatar un proceso de verdadero desarrollo, no sólo de mero crecimiento, presupone una actitud mental colectiva positiva, lo que Hirschman llamó decenios atrás "las ganas de desarrollarse", y es cierto, comunidades que sufren de una verdadera depresión, de una anomia colectiva à la Durkheim, generan espirales regresivos de tipo económico (en vez de círculos virtuosos) que imposibilitan el desarrollo ${ }^{10}$. Como lo dicen los publicistas, "pensar positivo" es parte de la fórmula del éxito. En términos de teoría de sistemas, estamos hablando de fenómenos de pro-alimentación de refuerzo, vulgo profecías auto-cumplidas.

Pero lo más importante mostrado por la Figura 4 tiene que ver con los conceptos de subsistemas generadores de complejidad y con el de capital intangi-

Figura 4. Desarrollo territorial endógeno.

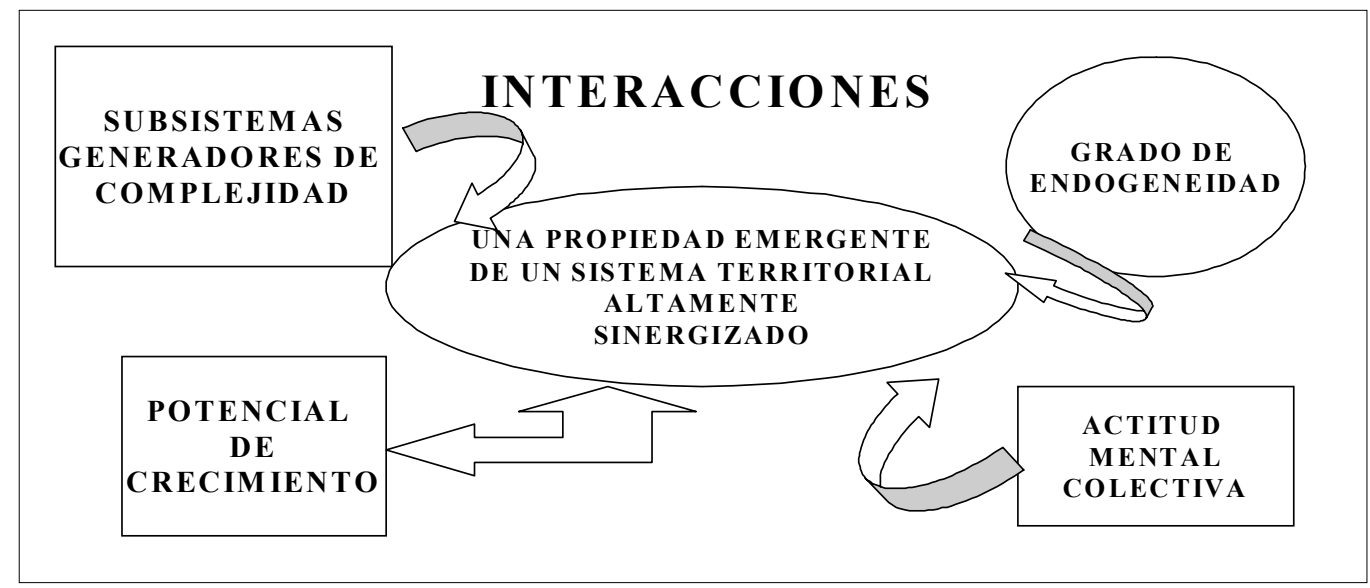

${ }^{8}$ Son muchos los nombres que han tenido responsabilidad en esta transformación: Lebret, Seers, Furtado, Hirschman, Sen, Maturana, Gali, y tantos otros.

${ }^{9}$ Recursos morales (Hirschman), activos relacionales (Storper, Camagni), capitales intangibles (Boisier), etc.
${ }^{10}$ No en balde durante el año 2001 en Chile se habló mucho acerca de una "recesión psicológica" que parece afectar al país. 
ble. El desarrollo es una emergencia sistémica o una propiedad emergente de un sistema territorial que contiene una muy elevada sinapsis y en el cual se ha introducido negentropía bajo la forma de sinergia cognitiva. Los subsistemas generadores de complejidad son sólo enunciados acá por razones de espacio: el subsistema axiológico, subliminal, decisional, organizacional, procedimental, de acumulación ${ }^{11}$. Por otro lado, y admitido, como se dijo, el carácter intangible del desarrollo (como el logro de un ambiente que potencia la transformación de los seres humanos en personas humanas, se recordará), se atiene a la lógica sostener que entonces sus factores causales serán de igual dimensión, es decir, intangibles y subjetivos. Como se puede mostrar que en casi cualquier territorio organizado existe un amplio conjunto de tales factores y como ellos pueden ser sometidos a un ejercicio taxonómico que entregue categorías relativamente homogéneas en su interior, ellas son llamadas "capitales intangibles". Boisier (1999) ha trabajado diez categorías: capital cognitivo, simbólico, cultural, social, cívico, institucional, psicosocial, humano, y mediático. Estas variadas formas son o deben ser articuladas con fuerza y direccionadas mediante el uso del capital sinergético $^{12}$, de manera de introducir un alto nivel de complejidad y sinergia en el sistema, pre-requisito del desarrollo. En términos operacionales se introduce acá la noción y la práctica de un proyecto político para ejecutar esta tarea.

Por último, la Figura 4 apunta a la necesidad de endogeneizar los procesos de cambio (crecimiento y desarrollo) en el territorio. En relación al crecimiento económico, ya descrito como altamente exógeno, es imprescindible intentar introducir un cierto grado de endogeneidad, alcanzable mediante la negociación y la promoción; en relación a los capitales intangibles y al propio desarrollo, su carácter intrínsecamente endógeno debe ser potenciado permanentemente. Como se dice en la propuesta estratégica de la Provincia del Neuquén en Argentina, NEUQUÉN 2020, "si el desarrollo es un producto de la propia comunidad, no serán otros, sino sus

\footnotetext{
(2003).

${ }^{11}$ Una exposición en detalle se encuentra en Boisier

${ }^{12}$ Una extensa discusión acerca de estos conceptos se encuentra en casi todos los últimos trabajos del autor.
}

miembros quienes lo construyan" (COPADE, 1997).

El concepto de endogeneidad (Boisier, 2000a; Vázquez-Barquero, 2001, entre otros), muy a la moda en círculos académicos, hay que entenderlo como desplegado en cuatro planos sociales que se intersectan. En primer lugar, la endogeneidad debe entenderse como una creciente capacidad territorial para optar por estilos de desarrollo propios y para poner en uso instrumentos de política adecuados a tales estilos ${ }^{13}$; como es claro, este plano de endogeneidad se asocia estrechamente a la descentralización. En segundo, la endogeneidad se entiende como una capacidad del territorio para apropiarse de una parte creciente del excedente económico generado allí para ser reinvertido in situ (a fin de dar soporte temporal a un crecimiento basado en una matriz productiva más y más diversificada); nuevamente esta capacidad es una función directa del nivel de descentralización radicado en el territorio $^{14}$. En tercer lugar, la endogeneidad dice relación con la capacidad del territorio para generar sus propios impulsos de cambio tecnológico, capaces de modificar cualitativamente su funcionamiento, un asunto asociado a la capacidad para establecer y poner en funcionamiento un sistema local de $\mathrm{C} \& \mathrm{~T}$. En cuarto lugar, la endogeneidad sólo es posible en el marco de una cultura productora de identidad territorial, a partir de la cual los activos intangibles ${ }^{15}$ potencian la competitividad territorial.

No cabe duda alguna: en la sociedad del conocimiento cambia o debe cambiar radicalmente la forma en que un territorio se plantea e interviene sus propios procesos de cambio-crecimiento y desarro-

\footnotetext{
${ }^{13}$ Me parece importante subrayar que la mayoría de las regiones debieran mostrar posibilidades de desarrollo que se distinguen del estilo del país. No se puede pensar en desarrollos miméticos reducidos a escala, pero no se me escapa el conflicto político que ello puede provocar, el que hay que canalizar positivamente.

${ }^{14}$ Es el territorio quien debe apropiarse del excedente, no importa si lo hace a través del sector público, por la vía tributaria, o del sector privado, por la vía de utilidades no distribuidas, o una combinación de ambas formas.

${ }^{15}$ Concepto algo diferente a "capitales intangibles". Los activos intangibles, marcas, derechos de propiedad, denominaciones de origen, calidad organizacional, y otros, son discutidos en Morgan (2001).
} 
llo-, y ello va de la mano con una imprescindible descentralización, cuya naturaleza y alcance exactos dependen más de la casuística que de normas generales.

\section{Modernizar la gestión social del territorio sin caer en un academicismo estéril}

En la sociedad del conocimiento, lo más importante es... ¡ iel conocimiento! Como lo sostiene Dror (1996), "deben hacerse vigorosos esfuerzos para elevar el nivel de entendimiento popular en relación a temas complejos" (123), y no hay tema social más complejo e importante que el propio desarrollo. También Stiglitz (2000) señala que "el éxito de una economía basada en el conocimiento también requerirá de una ciudadanía altamente educada, con fuertes habilidades cognitivas, y de una efectiva red descentralizada de comunicaciones" (103).

Ambos autores se refieren en definitiva a los necesarios cambios en los modelos mentales con los que trabajan los "operadores del desarrollo", desde los agentes sociales de base hasta las más altas autoridades políticas, y ello apunta a un "saber" actualizado.

Pero no se trata de transformar a los agentes de desarrollo en académicos, poseedores de un conocimiento acabado y altamente abstracto, aunque la teoría, bien entendida, sólo puede favorecer la eficiencia de la acción. Tampoco se trata de caer nuevamente, como sucedió notablemente en los años ' 60 , en la ilusión del racionalismo iluminista a ultranza, porque hacer gobierno, y de eso se trata, no depende sólo de un adecuado conocimiento, sino de su adecuada combinación con el arte de la política.

¿Cuánto conocimiento es necesario? La respuesta es en principio sencilla. Se requiere sólo del conocimiento pertinente, es decir, de una cantidad de conocimiento capaz, como ya fue indicado, de permitir el surgimiento del pensamiento complejo y contemporáneo en el análisis y en la acción en materia de cambio territorial.

Claramente surge ahora una cuestión praxeológica, es decir, ¿̨ómo se socializa un conoci- miento pertinente? Mi sugerencia basada en mi experiencia apunta a la utilización del constructivismo lingüístico, es decir, el uso sistemático de la palabra y del discurso para simultáneamente crear sujetos y realidades hasta generar una sinergia cognitiva ${ }^{16}$, que dé paso al consenso y, mediante él, al poder político, insumo indispensable para sacar la propuesta del "gabinete de las utopías". Esto debe organizarse mediante el establecimiento de conversaciones sociales (conversaciones profesionalmente estructuradas entre actores/sujetos).Como lo señala el PNUD (2000) en su Informe sobre Desarrollo Humano en Chile: "Sin conversaciones, públicas y privadas, que tengan como objeto a la sociedad, no habrá aspiraciones colectivas. Esto significa que será necesario fortalecer, por una parte, las dinámicas de la conversación social [...] Al mismo tiempo, para que la sociedad misma sea objeto de aspiraciones, debe afincarse el convencimiento de que la sociedad es un objeto en construcción permanente y que sus artífices son los sujetos concretos".

El paso desde la conversación a la acción consistirá entonces en la preparación y ejecución de un proyecto político de cambio para el territorio en cuestión ${ }^{17}$.

Si el desarrollo (territorial) puede ser considerado como una propiedad emergente de un sistema (espacial, social, económico, tecnológico, cultural) de alta complejidad, un proyecto concebido para hacer una verdadera "ingeniería de las intervenciones territoriales" debe inducir la intervención en aquellas cuestiones que sustentan una emergencia sistémica: conexiones, conectividad, recursividad, energía y otras, cuestiones todas vinculadas con la teoría dinámica de sistemas, con la lógica difusa, con la irreversibilidad temporal y con el caos. Si esto es efectivamente así, hay que hacer una divisoria de aguas entre dos tipos de tareas que el órgano político territorial debe abordar: tareas de administración, que son normalmente cotidianas, rutinarias,

${ }^{16}$ Definida como una capacidad colectiva para alcanzar objetivos colectivos democráticamente establecidos, capacidad basada en compartir una misma interpretación acerca de la estructura y dinámica de los procesos sobre los cuales será necesario intervenir. Véase Boisier (2000b).

${ }^{17}$ Cuya descripción y comentario escapa al alcance de este documento. 
de corto plazo y orientadas a cuestiones de orden material (para las cuales también es necesario un mejor conocimiento, por ejemplo, acerca de preparación de proyectos, presupuestos, etc.), y tareas propias de gobierno, más sustantivas, más estructurales, de mayor alcance temporal, más innovativas, más políticas porque tienen que ver con el poder y con requerimientos extraordinarios de conocimiento. Aquí no cabe la rutina, como bien lo dice Hirschman (1999): "Es verdad, el enemigo principal es precisamente la ortodoxia; repetir siempre la misma receta, la misma terapia, para curar tipos de enfermedades diferentes; no admitir la complejidad, desear reducirla a toda costa, mientras las cosas reales son siempre un poco más complicadas" (111).

Finalmente, uno de los desafíos más importantes que enfrenta cualquier sociedad en desarrollo es lograr que éste se alcance a lo largo y a lo ancho de su geografía y que su responsabilidad sea compartida por la sociedad civil y por el Estado. Asociatividad es el nombre del juego, pero para jugar se exigirá ahora a los jugadores conocimiento y autonomía; no es un juego para aficionados ni para subordinados. Como muy bien lo dice una alta funcionaria de la DATAR de Francia: "La noción de espacio hecho a 'sangre fría', reducida a sus características físicas y abstractas, poco a poco ha sido reemplazada por la noción de territorio hecho a 'sangre caliente', que se califica gracias a la acción colectiva de los trabajadores, de las colectividades, de las empresas y de las administraciones" (Pommier, 2001: 62).

Lo que está en juego es la democracia, la gobernabilidad, la gobernanza, y el desarrollo mismo en un marco institucional y cultural en el cual sea posible la diversidad dentro de la unidad, según la fórmula clásica de Eco (56) en "El nombre de la rosa": "Porque con tal sabiduría el arte los había combinado en armónica conjunción, iguales en la variedad y variados en la unidad, únicos en la diversidad y diversos en su perfecto ensamblaje" (56).

Nada de ello es posible sin colocar el esfuerzo de desarrollo en su lugar y en manos de la gente, es decir, nada de ello es posible sin una adecuada y flexible combinación de descentralización y centralización. ¡Hay que bajar a tierra la todavía etérea discusión sobre desarrollo!

\section{Referencias bibliográficas}

Boisier, S. (1991). "La descentralización: un tema confuso y difuso”. Nolhen, D. (ed.), Descentralización política y consolidación democrática. Caracas: Síntesis/Editorial Nueva Sociedad.

(1996). "Modernidad y territorio". Cuadernos del ILPES, 42.

(1999). "El desarrollo territorial a partir de la construcción de capital sinergético". Estudios Sociales, 99.

(2000a). "Desarrollo (local): ¿de qué estamos hablando?” Estudios Sociales, 103.

(2000b). Conversaciones sociales y desarrollo regional. Talca: Ediciones Universidad de Talca.

(2001). “Crónica de una muerte frustrada” (mimeo).

(2003). "¿Y si el desarrollo fuese una emergencia sistémica?” Ciudady Territorio. Estudios Territoriales, 138.

Brewer-Carías, A. (1998). "Descentralización y democracia: una reflexión obligada en Venezuela”. Mascareño, C. (coord.), Descentralización. Gobierno y democracia. Caracas: GLOCAL/ CENDES.

Cheema G. S. \& D. A. Rondinelli (1983). Decentralization and development. Poolicy implementation in developing countries. Beverly Hills: SAGE.

COPADE (1997). "Neuquén 2020. Crisis y oportunidad”. Documento Preliminar. Neuquén: Secretaría de Estado del COPADE.

COPRE (1989). La descentralización. Una oportunidad para la democracia. Caracas: Comisión Presidencial para la Reforma del Estado.

DATAR (2001). Aménager la FRANCE de 2020. Paris: Délégation à l'Aménagement du Territoire et à l'Áction Régionale.

Dror, Y. (1996). La capacidad de gobernar. Informe al Club de Roma. México: F.C.E.

Eco, U. (1984). El nombre de la rosa. Madrid: Lumen.

Finot I. (2001). Descentralización en América Latina: teoría y práctica. Santiago: CEPAL, Serie Gestión Pública.

Frei Ruiz-Tagle, E. (1996). Ideas para el diálogo democrático. Santiago: VI Cumbre Iberoamericana de Jefes de Estado y de Gobierno, Presidencia de la República. 
Granovetter, M. (1973). "The strength of weak ties". American Journal of Sociology, 78, 6.

Hirschman, A. (1999). A través de las fronteras. Los lugares y las ideas en el transcurso de una vida. México: F.C.E.

Morgan, K. (2001). "The exaggerated death of geography: Localized learning, innovation and uneven development". Paper presented to The Future of Innovation Studies Conference, The Eindhoven Centre for Innovation Studies, Eindhoven University of Technology, September 2001.

OECD (2001). Territorial Outlook 2001. Paris: OECD.

PNUD (2000). Desarrollo Humano en Chile. Santiago: Programa de Naciones Unidas para el Desarrollo.

Pommier, P. (2001). "Los desafíos del ordenamiento territorial en Francia a la hora de la mundialización”. AAVV, Descentralización y de- sarrollo regional. Santiago: Ministerio del Interior, Subsecretaría de Desarrollo Regional y Administrativo.

Stiglitz, J. (2000). "Participación y desarrollo: perspectivas desde el paradigma integral de desarrollo". Instituciones y Desarrollo, 7.

Vázquez-Barquero, A. (2001). "Desarrollo endógeno”. Vázquez-Barquero, A. \& O. Madoery (comps.), Transformaciones globales, instituciones y políticas de desarrollo local. Buenos Aires: Homo Sapiens.

Véliz, C. (1984). La tradición centralista de América Latina. Barcelona: Ariel.

Work, R. (2001). "Decentralization, governance and sustainable regional development”. Stohr, W. B., J. Edralin y D. Mani (eds.), Decentralization, governance and the new planning for local-level development. Greenwood Publishers: New Regional Development Paradigms. 